\title{
Association between Handedness and Socio-demographical factors among School Children:
}

\author{
Dr. Susie Jeyalyn David ${ }^{1}$, Dr. S. Rajasankar ${ }^{2}$, Dr.V.Venkatesh Gobi ${ }^{3}$ \\ Mr. M.Ramkumar ${ }^{4}$, Dr. Lenin $S^{5}$, Dr. Hebbal GV ${ }^{6}$ \\ ${ }^{1}$ Phd-Scholar (Medical Anatomy), Bharath University, Chennai. \\ ${ }^{2}$ Professor, Velammal Medical College \& Hospital, Madurai. \\ ${ }^{3}$ Associate Professor, Sivaraj Homeopathy Medical College, Salem. \\ ${ }^{4}$ Tutor, Velammal Medical College \& Hospital, Madurai. \\ ${ }^{5}$ Assistant Professor,Kanyakumari Government Medical College, Kanyakumari. \\ ${ }^{6}$ Professor,Sree Mookambika Institute Of Medical Sciences,Kulasekharam, Kanyakumari.
}

\begin{abstract}
Symmetry is defined as correspondence in size, shape and relative position of parts on opposite sides of a dividing line or median plane. Handedness is one of the most obvious functional asymmetries. Approximately $90 \%$ of all subjects are right handed, the remaining $10 \%$ of the population are left handed. Lefthandedness results from perinatal left hemisphere neurological damage, due to an oxygen deficiency induced by birth stress. Studies do show that there is a predictable relationship between laterality and sleep disturbance. There are several developmental factors implied in handedness in humans. There have been studies using one or some measures but using a wide range of the measures is rare in research literature. Against this backdrop this study examines the association between handedness and various socio-demographical factors.
\end{abstract}

Keywords: Handedness, left handers, right handers.

\section{Introduction}

Laterality refers to the structure and function of paired organs or of two similarly arranged areas of non-paired organs, distributed on the right and left sides. ${ }^{1}$ Hand preference, which is a peripheral measure of hemispheric asymmetry, has been found to be a robust phenomenon. Research has shown that cerebral asymmetries act in different ways for left- and right-handers. ${ }^{2}$ Out of all the measures of hemispheric asymmetry, hand preference has been very conspicuous and has received a great deal of attention by researchers as well as common folk.

The brain mechanism underlying handedness is such that handedness is contralaterally related to the two hemispheres, left hand to the RH and right hand to the LH. There is evidence that left- and right-handers differ when compared on a variety of behavioural measures. ${ }^{3}$ Left-handedness has been reported to be common in a variety of disorders that presumably reflect developmental abnormality. These include neural tube defects, autism ${ }^{4}$ psychopathy, cleft palate syndrome, stuttering ${ }^{5}$ and schizophrenia ${ }^{6}$ However, it should be noted that negative results have also been reported (Bishop 1990). If an individual has been subjected to a birth stressor or an atypical intrauterine environment, and if the stressor is mild enough, left-handedness might just be a behavioural marker linked to a syndrome caused by minor abnormalities in neurological development. ${ }^{7}$

Left-handedness results from perinatal left hemisphere neurological damage,due to an oxygen deficiency induced by birth stress (e.g. premature birth, prolonged labour, Rhesus incompatibility, breech delivery, multiple birth, respiratory distress syndrome, primiparity,maternal age) ${ }^{8}$ There is an excess of lefthanders in babies with a history of birth stress ${ }^{9}$, and in individuals with neurological impairments of diverse kinds. ${ }^{10}$ Researchers have found a higher average age for the mothers of left-handed children ${ }^{11}$ and also have observed more left-handed than right-handed children for primiparous mothers aged 39 years orolder. ${ }^{12}$

Low birth weight could play a key role in the health problems associated with left-handedness. The mechanism that has been proposed most frequently to explain an association between left-handedness and low birth weight involves early brain damage. Indeed low birth weight greatly increases the risk of early brain damage.$^{13}$

Environmental factors could also exert selection forces on left-handers. The frequency of left-handers has been reported to vary according to age classes. ${ }^{14,15}$ This could be interpreted as due to changing patterns of social norms: for example, writing handedness was submitted to more social pressures in the past than in the present ${ }^{16}$

Many Asian countries encourage or force their children to become right-handed due to cultural perceptions of bad luck associated with the left hand. In India and Indonesia, it is considered rude to eat with the left hand. ${ }^{17}$ Many diverse studies on handedness have been conducted by researchers from various fields such as medicine, neurology and psychology. Experiment do show that there is a predictable relationship between laterality and sleep disturbance. Left-sided individuals are more likely than right-sided individuals to report difficulties falling asleep and frequent night wakenings. ${ }^{7}$ Although some data remain controversial, several 
hormonal, cultural and developmental factors have been found to be associated with handedness. Here, we attempt to find the correlation between handedness and various socio-demographic factors and various other factors in brief.

\section{Materials \& Methods}

A sample of 210 student volunteers were selected from various schools in Kanyakumari District for the study. They were selected in such a way that the sample for our study consists of equal number of right handed and left handed volunteers. The sample selected was gender free between the age group of 13 to 18 years, from the local schools. Care was taken to exclude the volunteers, with any physical deformity or disability. The parents of these volunteers were informed about the intended study and its procedures. Informed and written consent was obtained from the parents of each volunteer before inclusion in this protocol, which received the approval of the Institutional Human Ethical Committee.

- Handedness was assessed by Edinburgh Handedness Inventory ${ }^{18}$

The questionnaire was distributed to all participants along with the reassurance of confidentiality of their response. The questionnaires were retrieved after which these questionnaires were scored and properly analysed using the statistical software called IBM statistics-20. The P-Values less than or equal to $0.05(\mathrm{P} \leq 0.05)$ were considered as statistically significant.

\section{Results}

Table-1: Homogeneity of two groups in respect of their sex, religion and school of studying:

\begin{tabular}{|c|c|c|c|c|c|c|c|c|}
\hline \multirow{2}{*}{ Variables } & \multirow{2}{*}{ Components } & \multicolumn{2}{|c|}{ Left, $n=105$} & \multicolumn{2}{|c|}{ Right, $n=105$} & \multirow{2}{*}{$\chi^{2}$} & \multirow{2}{*}{ df } & \multirow{2}{*}{ Sig } \\
\hline & & Fre & $\%$ & Fre & $\%$ & & & \\
\hline \multirow{2}{*}{ Gender } & Male & 65 & 61.9 & 65 & 61.9 & \multirow{2}{*}{0.020} & \multirow{2}{*}{1} & \multirow{2}{*}{$P>0.05$} \\
\hline & Female & 40 & 38.0 & 40 & 38.0 & & & \\
\hline \multirow{3}{*}{ Religion } & Hindu & 52 & 49.5 & 53 & 50.5 & \multirow{3}{*}{2.286} & \multirow{3}{*}{2} & \multirow{3}{*}{$\mathrm{P}>0.05$} \\
\hline & Muslim & 17 & 16.2 & 10 & 9.5 & & & \\
\hline & Christian & 36 & 34.3 & 42 & 40.0 & & & \\
\hline \multirow{3}{*}{ Studying school } & Aided & 24 & 22.9 & 22 & 21.0 & \multirow{3}{*}{0.358} & \multirow{3}{*}{2} & \multirow{3}{*}{$\mathrm{P}>0.05$} \\
\hline & CBSE & 33 & 31.4 & 37 & 35.2 & & & \\
\hline & Matriculation & 48 & 45.7 & 46 & 43.8 & & & \\
\hline
\end{tabular}

The variables of the study subjects like gender religion and studying schools were described and the homogeneity between the two groups were tested in the above table-1. There was no significant differences between the two groups in terms of participation percentage and hence they are comparable groups $(\mathrm{P}>0.05)$.

Table-2: Association between handedness with relatives:

\begin{tabular}{|c|c|c|c|c|c|c|c|}
\hline \multirow{2}{*}{ Relatives } & \multicolumn{6}{|c|}{ Handedness } & \multirow{2}{*}{ Results } \\
\hline & Left & $\%$ & Right & $\%$ & Total & $\%$ & \\
\hline Yes & 45 & 42.9 & 14 & 13.3 & 59 & 28.1 & \multirow{3}{*}{$\begin{array}{l}\chi^{2}=22.652 \\
\mathrm{df}=1 \\
P<0.001\end{array}$} \\
\hline No & 60 & 57.1 & 91 & 86.7 & 151 & 71.9 & \\
\hline Total & 105 & 100.0 & 105 & 100.0 & 210 & 100.0 & \\
\hline
\end{tabular}

The above table -2 shows the association between left and right handers and relatives. The relatives of left and right handers had the same hand usage was $42.9 \%$ and $13.3 \%$ respectively and the no relatives were using the same hand were $57.1 \%$ and $86.7 \%$.The above relationship was statistically very highly significant $(\mathrm{P}<0.001)$.

Table-3: Association between handedness with economic status:

\begin{tabular}{|c|c|c|c|c|c|c|c|}
\hline \multirow{2}{*}{ Economical status } & \multicolumn{6}{|c|}{ Handedness } & \multirow{2}{*}{ Results } \\
\hline & Left & $\%$ & Right & $\%$ & Total & $\%$ & \\
\hline L Middle & 45 & 42.9 & 39 & 37.1 & 84 & 40.0 & \multirow{4}{*}{$\begin{array}{l}\chi^{2}=1.229 \\
\mathrm{df}=1 \\
\mathrm{P}=0.541\end{array}$} \\
\hline U Middle & 58 & 55.2 & 62 & 59.0 & 120 & 57.1 & \\
\hline Upper & 2 & 1.9 & 4 & 3.8 & 6 & 2.9 & \\
\hline Total & 105 & 100.0 & 105 & 100.0 & 210 & 100.0 & \\
\hline
\end{tabular}

The association between the handedness with the economical status of the family was stated in the table- 3 . There was no significant association was identified between the handedness with family economical status $(\mathrm{P}>0.05)$. 
Table-4: Association between handedness with food habits:

\begin{tabular}{|c|c|c|c|c|c|c|c|}
\hline \multirow{2}{*}{ Food habits } & \multicolumn{6}{|c|}{ Handedness } & \multirow{2}{*}{ Results } \\
\hline & Left & $\%$ & Right & $\%$ & Total & $\%$ & \\
\hline Non-vegetarian & 92 & 87.6 & 96 & 91.4 & 188 & 89.5 & \multirow{3}{*}{$\begin{array}{l}\chi^{2}=0.812 \\
\mathrm{df}=1 \\
\mathrm{P}=0.367\end{array}$} \\
\hline Vegetarian & 13 & 12.4 & 9 & 8.6 & 22 & 10.5 & \\
\hline Total & 105 & 100.0 & 105 & 100.0 & 210 & 100.0 & \\
\hline
\end{tabular}

The association between the handedness with the food habit was stated in the above table- 4 . There was no significant association identified between the handedness with the food habit $(\mathrm{P}>0.05)$.

Table-5: Association between handedness with type of child birth delivery:

\begin{tabular}{|l|l|l|l|l|l|l|l|}
\hline \multirow{2}{*}{$\begin{array}{l}\text { Type } \\
\text { Delivery }\end{array}$} & \multicolumn{4}{|l|}{ Handlers } & \multirow{2}{*}{ Results } \\
\cline { 2 - 7 } & Left & $\%$ & Right & $\%$ & Total & $\%$ & \\
\hline Cesarean & 43 & 41.0 & 23 & 21.9 & 66 & 31.4 & $\chi^{2}=22.652$ \\
\hline Normal & 62 & 59.0 & 82 & 78.1 & 144 & 68.6 & $\mathrm{df}=1$ \\
\hline Total & 105 & 100.0 & 105 & 100.0 & 210 & 100.0 & $\mathrm{P}<0.001$ \\
\hline
\end{tabular}

The table- 5 shows the relationship between type of child birth delivery and handedness. The child birth delivery of left and right handers by cesarean section was $41.0 \%$ and $21.9 \%$ respectively. Among the normally delivered subjects had $59.0 \%$ were left handers and $78.1 \%$ right handers. The association between the handedness and type of delivery was statistically very highly significant $(\mathrm{P}<0.001)$.

Table-6: Association between handedness with term of baby:

\begin{tabular}{|l|l|l|l|l|l|l|l|}
\hline \multirow{2}{*}{ Term of baby } & \multicolumn{9}{|l|}{ Handlers } & \multicolumn{3}{|l|}{} & \multirow{2}{*}{ Results } \\
\cline { 2 - 8 } & Left & $\%$ & Right & $\%$ & Total & $\%$ & \\
\hline Pre term & 10 & 9.5 & 4 & 3.8 & 14 & 6.7 & $\chi^{2}=2.755$ \\
\hline Full term & 95 & 90.5 & 101 & 96.2 & 196 & 93.3 & df=1 \\
\hline Total & 105 & 100.0 & 105 & 100.0 & 210 & 100.0 & $\mathrm{P}=0.097$ \\
\hline
\end{tabular}

The table- 6 states the association between term of baby and handedness. $9.5 \%$ of left handers and $3.8 \%$ of right handers were pre term babies . $90.5 \%$ of left handers and $96.2 \%$ of right handers were full term babies. The association between the handedness and term of babies was not statistically significant $(\mathrm{P}>0.05)$.

Table-7. Comparison of sleeping hours between the left and right handers:

\begin{tabular}{|l|l|l|l|l|l|l|l|}
\hline Handlers & $\mathrm{n}$ & Mean & SD & Difference & t & df & Significance \\
\hline Left & 105 & 8.2 & 1.2 & \multirow{2}{*}{0.1} & \multirow{2}{*}{0.706} & \multirow{2}{*}{208} & \multirow{2}{*}{$\mathrm{P}=0.481$} \\
\hline Right & 105 & 8.1 & 1.3 & & \\
\hline
\end{tabular}

The table - 7 compares the sleeping hours between the left and right handers. The left handers had the mean duration of sleeping $8.2 \pm 1.2$ hours and the right handers had the mean duration of sleeping $8.1 \pm 1.3$ hours. The difference between the mean durations was not statistically significant $\mathrm{P}>0.05$ ).

\section{Discussion}

The study of handedness in families is a first attempt to characterize the mechanism involved, since it allows assessment of the transmission of this trait across generations. Two right-handed parents produce fewer left-handed offspring than parents with any other handedness combination and two left-handed parents produce the highest proportion of left-handed children, i.e. approximately 30-40\%.$^{19,20}$ This suggests that hand preference could be transmitted by parents to their children, either at a genetic or learning level. In the present study the relationship between handedness and genetic factor was statistically very highly significant $(\mathrm{P}<0.001)$.

Hormonal factors associated with the intrauterine environment are a proposed source of development of left handedness. This theory is based on the assumption that prenatal sex hormones exert powerful influences on the central nervous system of the developing foetus. Specifically, high levels of testosterone during foetal development or heightened sensitivity to these prenatal hormones will disrupt neural development, causing a number of physiological changes, and also result in an increased likelihood of anomalous dominance, i.e. lefthandedness and/or weak lateralization. ${ }^{21,22}$

Low birth weight is associated with perinatal complications, neurological problems and a number of adult pathologies. There is evidence for an excess of left handedness among extremely low birth weight babies.$^{23}$ In 
the present study the association between the handedness and term of babies was not statistically significant $(\mathrm{P}>0.05)$. The most likely explanation for the increase in accidental death among left-handed men concerns their need to cope in a world full of righthanded tools, machines and instruments. ${ }^{24}$ The fact that the frequency of lefthandedness never reaches 50 percent in any human population investigated so far indicates that some costs associated with left-handedness must exist. ${ }^{25,26}$

Parents are the closest to their children especially in their early years. They need to be sensitized as to the uniqueness of left-handedness and helped to appreciate it. It is necessary that teachers especially those in nursery and primary schools be educated on left-handedness because they are usually the ones that spend most time with young children .So, the parents and teachers should be properly educated on this, so they do not turn the lefthanders into poorly impaired individuals as a result of punishment and force applied on these ones to change their handedness from left to right simply on the basis of societal rejection of left handedness.

\section{References}

[1]. Eysenck, H. J., Arnold, W., Wurzburg, R.G., \& Meili, B. (1972). Encyclopedia of Psychology, 2, (pp. 182 183). London: Search.

[2]. Annett, M. (1985). Left, right, hand and brain: The right shift theory. Hove, U.K: Lawrence Erlbaum.

[3]. Annett, M., \& Alexander, M. P. (1996). Atypical cerebral dominance: Predictions and tests of the right shift theory. Neuropsychologia, 34 (12), 1215-1227.

[4]. Dane, S. \& Balci, N. 2007 Handedness, eyedness and nasal cycle in children with autism. International Journal of Developmental Neuroscience. 25,223-226. (doi:10.1016/j.ijdevneu.2007.03.005)

[5]. Dellatolas, G., Annesi, I., Jallon, P., Chavance, M. \& Lellouch, J. 1990 An epidemiological reconsideration of the GeschwindGalaburda theory of cerebral lateralization. Archives of Neurology 47, 778-782.

[6]. Yeo, R. A. \& Gangestad, S.W. 1993 Developmental origins of variation in human preference. Genetica 89, 281296(doi:10.1007/BF02424521)

[7]. Coren, S. \& Searleman, A. 1987 Left sidedness and sleep difficulty: the alinormal syndrome. Brain and Cognition 6,184-192. (doi:10.1016/0278-2626(87)90119-9)

[8]. Bakan, P. 1971 Handedness and birth order. Nature 229, 195.(doi:10.1038/229195a0)

[9]. Schwartz, M. 1988 Handedness, prenatal stress and pregnancy complications. Neuropsychologia 26, 925-929.(doi:10.1016/00283932(88)90060-7)

[10]. Williams, C. S., Buss, K. A. \& Eskenazi, B. 1992 Infant resuscitation is associated with an increased risk of lefthandedness. American Journal of Epidemiology. 136, 277-286.

[11]. Coren, S. \& Porac, C. 1980 Birth factors and laterality: effects of birth order, parental age, and birth stress of four indices of lateral preference. Behavior Genetics. 10, 123-138. (doi:10.1007/BF01066263)

[12]. Smart, J. L., Jeffrey, C. \& Richard, B. 1980 A retrospective study of the relationship between birth history and handedness at six years. Early Hum. Dev. 4, 79-88. (doi:10.1016/0378-3782(80)90011-0)

[13]. Stewart, A. L. et al. 1999 Brain structure and neurocognitive and behavioural function in adolescents who were born very preterm. Lancet 353, 1653-1657. (doi:10.1016/ S0140-6736(98)07130-X)

[14]. Porac, C., Coren, S. \& Duncan, P. 1980 Life-span age trends in laterality. Journal of Gerontology. 35, 715-721.

[15]. Gilbert, A. N. \& Wysocki, C. J. 1992 Hand preference and age in the United States. Neuropsychologia 30, 601608.(doi:10.1016/0028-3932(92)90065-T)

[16]. Hugdahl, K., Satz, P., Mitrushina, M. \& Miller, E. N. 1993 Left-handedness and old age: do left-handers die earlier? Neuropsychologia 31, 325-333. (doi:10.1016/0028- 3932(93)90156-T)

[17]. Binns, Corey. "What makes a lefty: Myths and mysteries persist". Live Science.March 21, 2006.

[18]. Oldfield Rc. The assessment and analysis of handedness: The Edinburgh Inventory. Neuropsychologia 1971;9:97-113.

[19]. McManus, I. C. 1991 The inheritance of left-handedness. In Biological asymmetry and handedness (eds G. R. Bock \& J.Marsh), pp. 251-281. Chichester, UK: Wiley.

[20]. McKeever, W. F. 2004 An X-linked three allele model of hand preference and hand posture for writing. Laterality 9, 149-173.

[21]. Geschwind, N. \& Behan, P. 1982 Left-handedness: association with immune disease, migraine, and developmental learning disorder. Proceedings of the National Academy of Sciences USA 79, 5097-5100. (doi:10.1073/pnas.79.16.5097)

[22]. McManus, I. C. \& Bryden, M. P. 1991 Geschwind's theory of cerebral lateralization: developing a formal, causal model. Psychological Bulletin. 110, 237-253. (doi:10.1037/0033-2909. 110.2.237)

[23]. O’Callaghan, M. J., Tudehope, D. I., Dugdale, A. E., Mohay, H., Burns, Y. \& Cook, F. 1987 Handedness in children with birthweights below $1000 \mathrm{~g}$. Lancet 1, 1155. (doi:10.1016/S0140-6736(87)91719-3

[24]. Aggleton, J. P., Kentridge, R. W. \& Neave, N. J. 1993 Evidence for longevity differences between left handed and right handed men: an archival study of cricketers. Journal of Epidemiology and Community Health 47, 206-209. (doi:10.1136/jech.47.3.206)

[25]. Faurie, C., Schiefenho" vel, W., Le Bomin, S., Billiard, S. \& Raymond, M. 2005b Variation in the frequency of lefthandedness in traditional societies. Current Anthropology 46, 142-147. (doi:10.1086/427101)

[26]. Raymond, M. \& Pontier, D. 2004 Is there geographical variation in human handedness? Laterality 9, 35-52. 